\title{
Sweat glands module with integrated sensors designed for Additive Manufacturing
}

\author{
Ioan Turcin ${ }^{1,2^{*}}$, Ali Abdallah ${ }^{1}$, Cosmin Cosma $^{2}$, Thomas Thiebet $^{1}$, Daniela Zavec ${ }^{3}$, and \\ Nicolae Balc ${ }^{2}$ \\ ${ }^{1}$ CAMPUS 02 UAS/Degree Programmes in Automation Technology, 8010 Graz, Austria \\ ${ }^{2}$ Technical University of Cluj-Napoca, Machine Building Faculty, 400114 Cluj-Napoca, Romania \\ ${ }^{3}$ University of Maribor, Mechanical Engineering Research Institute, Laboratory for Intelligent \\ Manufacturing Systems, 2000 Maribor, Slovenia
}

\begin{abstract}
Lead by the results of our previous work, in which we designed the sweat glands prototype according to AM (Advanced Manufacturing) requirements, in this study we aimed to integrate the previously manufactured channels into a stereolithography (SLA)-manufactured module, in order to avoid support structures inside the channels and the model cavities. That was achieved by distributing the channels in the manner which approximates the sweat glands distribution on an equivalent real body part and to be able to adjust the sweat quantity, to the estimated sweat rates found in the literature. The manufactured module has integrated humidity and temperature sensors, which will allow an accurate quantitative assessment of the thermoregulation of the individual modules and the sweat glands prototype as a whole.
\end{abstract}

\section{Introduction}

The optimization of materials and the heat dissipation by evaporation as well as the evaluation of the steam water vapour resistance has caused a rapid expansion in industry, especially textile, which results in the need to develop more cutting-edge and accurate testing equipment. Advanced technologies have helped in designing different measuring and testing devices, to produce realistic results that relate to human thermal comfort and its interaction with the surroundings [1]. Additionally, different computer tools and modern software allowed the combination of the comparison of the obtained data from the tests with the modelling results using different testing equipment such us thermal manikin or sweating hot plate [2].

The present study focuses on designing a complex and anatomical sweat glands module that mimics a sweating area of a human body and the manufacturing of this module using stereolithography (SLA)-techniques. Additionally, the module includes slots for humidity and temperature sensor.

\footnotetext{
*Corresponding author: ioan.turcin@campus02.at
} 
With a mass of about 30-40 $\mu \mathrm{g}$, sweat glands appear over the entire body surface and are found within the first $3 \mathrm{~mm}$ of the skin. Their coils have a volume of around $0.004 \mathrm{~mm}^{3}$, are about $3.5 \mathrm{~mm}$ long and approximately $40 \mu \mathrm{m}$ in diameter [3].

Considering the fact that it is not possible to create sweat glands with the abovementioned dimensions using a standard SLA-system, due to resolution limitations, we concentrated on exchange surface and sweat rate thus designing a module that would bring the same amount of liquid to the selected surface.

According to the findings from [3], a standardized individual with a skin surface area of 1.8 $\mathrm{m}^{2}$, loses daily $0.6-2.3 \mathrm{~L}$ of insensible water, with the head and neck losing intermediate amounts (40-75 g.h $\left.{ }^{-1}\right)$ and with the hands (80-160 g.h $\left.{ }^{-1}\right)$ and feet $\left(50-150\right.$ g.h $\left.\mathrm{h}^{-1}\right)$ losing the most. The examples of regional distribution of sweat glands and sweat rates are shown in Table 1.

Table 1. Regional distribution of sweat glands and sweat rates [3]

\begin{tabular}{|c|c|c|c|c|}
\hline Site & $\begin{array}{c}\text { Density } \\
(\text { glands.cm }\end{array}$ & $\begin{array}{c}\text { Surface } \\
\text { area }_{\left(\mathbf{c m}^{2}\right)}\end{array}$ & $\begin{array}{c}\text { Sweat rate rest } \\
\left(\mathbf{m g . m i n}^{-1}\right)\end{array}$ & $\begin{array}{c}\text { Sweat rate exercise } \\
\left(\mathbf{m g . m i n}^{-\mathbf{1}}\right)\end{array}$ \\
\hline Armpit & 84 & 196.2 & 0.312 & 0.850 \\
\hline Abdomen & 102 & $1,349.7$ & 0.346 & 1.053 \\
\hline Chest & 94 & $1,374.0$ & 0.393 & 1.403 \\
\hline Back & 103 & $2,244.1$ & 0.564 & 1.658 \\
\hline
\end{tabular}

The calculations of the regional distribution are normalized to the unisexual reference adult $\left(1.702 \mathrm{~m}, 70 \mathrm{~kg}\right.$, and a body surface area of $\left.1.807 \mathrm{~m}^{2}\right)$. The conditions for the passive heating predictions relate to a whole-body sweat rate of $0.4 \mathrm{~L} \cdot \mathrm{h}^{-1}$ and a core temperature of $37.2^{\circ} \mathrm{C}$ (with an elevation of $0.6^{\circ} \mathrm{C}$ above the baseline). At one external work rate of $125 \mathrm{~W}$ during the exercise, the sweat rate was approximately $1.0 \mathrm{~L} \cdot \mathrm{h}^{-1}$ and the core temperature was $38.8^{\circ} \mathrm{C}$ (elevation of $2.2^{\circ} \mathrm{C}$ ) [3].

As a technically demanding design and an anatomically complex area of the human body, the armpit was selected to be developed as a sweat glands module.

Fig. 1. Torso with implemented sweat glands modules in the armpit

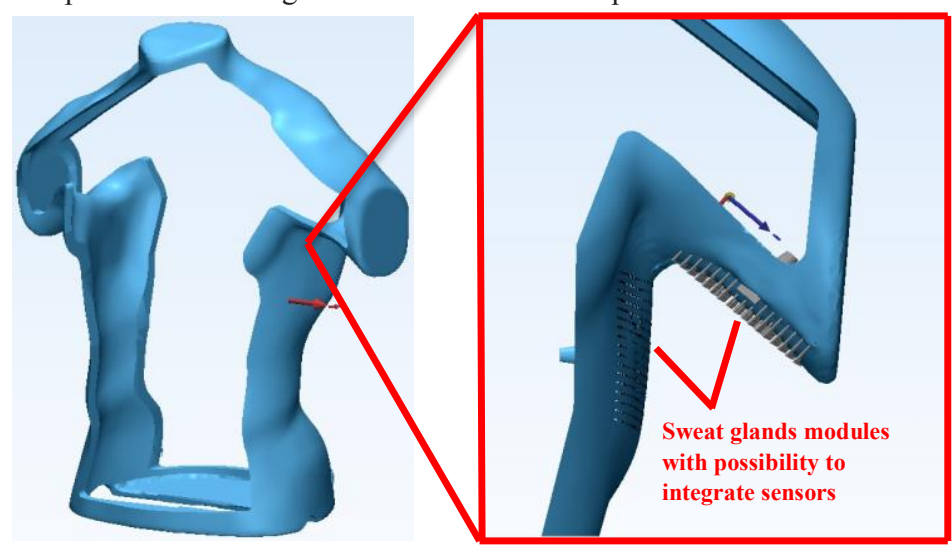

Fig. 1 depicts the possibility of implementing sweat glands modules with integrated sensors into an armpit of a torso. 


\section{.2 Designing and manufacturing the sweat glands module prototype}

AM presents an efficient solution to produce directly designed complex parts, enabling a good integration of sensors and fluid flow channels into the prototype, which could be cost-efficiently manufactured.

Taking into account our previous study [4], based on our expertise in the design for AM [5], [6] and SLA specifications provided by FormLabs [7], we designed a complex sweat glands module.

The central inlet was designed with a hole diameter of $3.20 \mathrm{~mm}$ (see Fig. 2a). The outlet holes (sweat glands) have a diameter of minimum of $0.60 \mathrm{~mm}$, because smaller diameters may close off during the manufacturing process, also the post-processing, e.g. cleaning, is very difficult. The walls of the part are minimum $0.90 \mathrm{~mm}$ and they could be reduced to $0.40 \mathrm{~mm}$ if needed. Using a linear pattern function, the design of outlets was distributed on the surface (Fig. 2b). Inside the part, we designed the flow channels to achieve a robust structure and to maintain an efficient distribution of the liquid flow. Moreover, the shape of the channels was adapted to the SLA-process requirements. The design of the internal flow channels was developed to avoid the need of supports structures, in accordance with printing orientation and contains the integrated cavities for humidity and temperature sensors. These channels are interconnected.

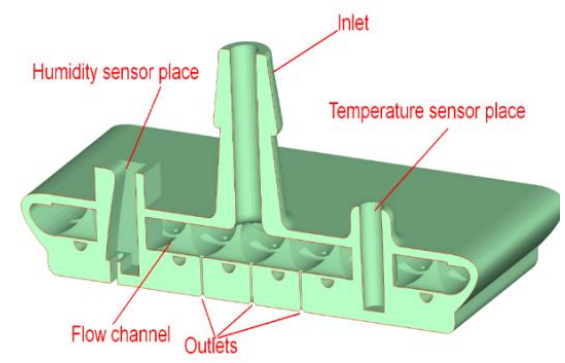

a)

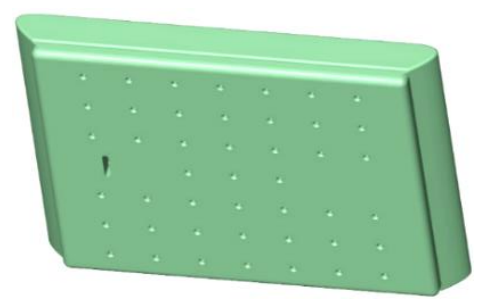

b)

Fig. 2. Sweat glands module: a) cross section and components; b) outlets side view

Additionally, the minimum hole diameter and the distance between two walls were considered to develop as many outlets as possible via SLA, in order to mimic a human sweat glands region. Across the skin surface of an individual, the densities vary widely, with the highest density on surfaces of fingers (530 glands/cm2) and the lowest on the upper lip, chest or posterior (16-30 glands/cm2) thigh. The same person could possess two million functional glands [3].

Based on various scientific papers $[5,8,9,10]$, which have shown that a wide range of complex parts, prototypes and different shapes can be used in a broader range of applications, SLA has proven to be a suitable AM technology, for producing the currently designed sweat glands module. However, the forming principles of the AM differ from those of traditional methods, such as casting or cutting technologies $[11,12,13,14]$ and adapted design for AM rules are demanded.

The designed module was prepared to be printed with two types of photo-polymers: clear resin and elastic resin from FormLabs [15]. The post-processing procedure goes beyond the normal required cleaning for SLA parts. Special care should be taken to rinse all the channels from the resin residue using isopropyl alcohol, and adding the extra step of the ultrasonic cleaning to ensure that all the channels are open and they do not clog during the post-processing UV hardening. 


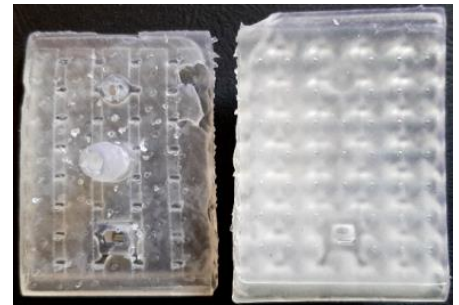

a)

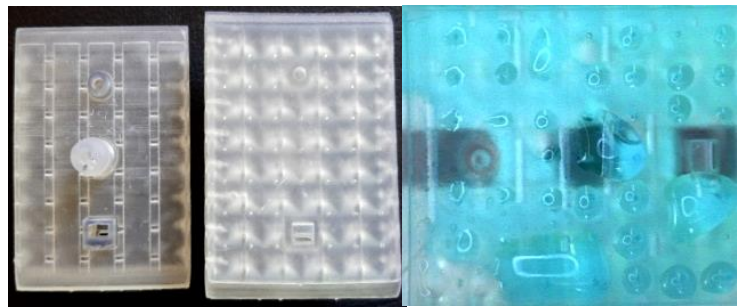

b)

Fig. 3. Sweat glands module manufactured and post-processed: a) elastic resin; b) clear resin

After the post-processing, we decided to proceed with the clear resin (Fig. 3b) manufactured module. This module offers more stability in comparison to the elastic resin (Fig. 3a) manufactured module and provides an easy, robust way to integrate both, humidity and a temperature sensor. In addition, the body contour can directly be integrated in the printed part regardless of complexity.

\section{Designing and manufacturing the anatomical armpit sweat glands module with integrated sensors}

The armpit is the area on the human body right under the joint, where the arm connects to the shoulder [16]. Following the technological observations regarding the SLAmanufacturing process, the virtual model was redesigned, taking into account all the required aspects and the integration into the axilla area. SolidWorks, Meshmixer and Creo software was used, to design the sweat glands module. For editing and modifying the STLformat of the model by adding artificial construction, the Boolean operation offers a flexible tool [17]. The main activities developed to redesign and to integrate the sweat glands modules into the complex anatomical model were:

- Creating the anatomical model of armpit by cutting it from the human torso model developed previously [3]; the considered region is at real scale (1:1) of a healthy adult;

- Redesigning the sweat glands modules by increasing the overall dimensions to $90 \times 67$ $\mathrm{mm}$ (370 outlets) and $75 \times 67 \mathrm{~mm}$ (270 outlets); the slots for the temperature and humidity sensors were also included.

- Design of a negative sweat glands module (fully solid inside), for subtraction operation from the anatomical shape of the virtual axilla-arm area;

- Subtraction procedure with the previous negative models in the virtual axilla-arm area (boolean operation in STL-format file). The result is illustrated in Fig. 4a;

- Union operations between the anatomical model obtained previously and the CAD sweat glands modules (Fig. 4b);

- Cutting the outlets channels that exceed the anatomical surface of the substrate;

- Reducing the dimension of the final model to be SLA processed by FormLabs equipment;

- Correcting all the surface errors, which appeared in the final virtual model with complex and anatomical surfaces (over 15,000 surface defects).

In order to avoid thin surfaces in the model (down to $0.1-0.2 \mathrm{~mm}$ ), which could affect the manufacturing a thickness analysis was made (Fig. 4c). Over 90,000 surfaces were analyzed and the histogram field was between $0-10 \mathrm{~mm}$. It was observed that only limited areas contain surfaces under $0.50 \mathrm{~mm}$. The area of outlets channels has values below 0.60 $\mathrm{mm}$ (details in the histogram, green color). 


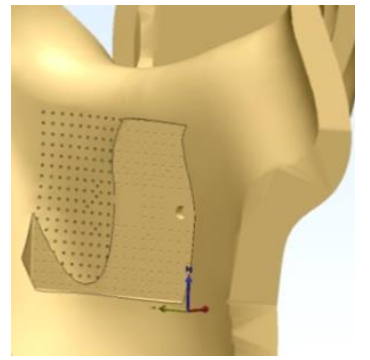

a)

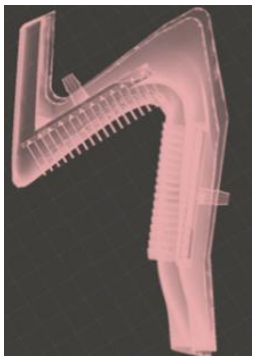

b)

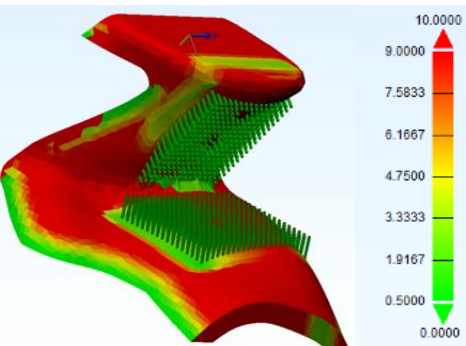

c)

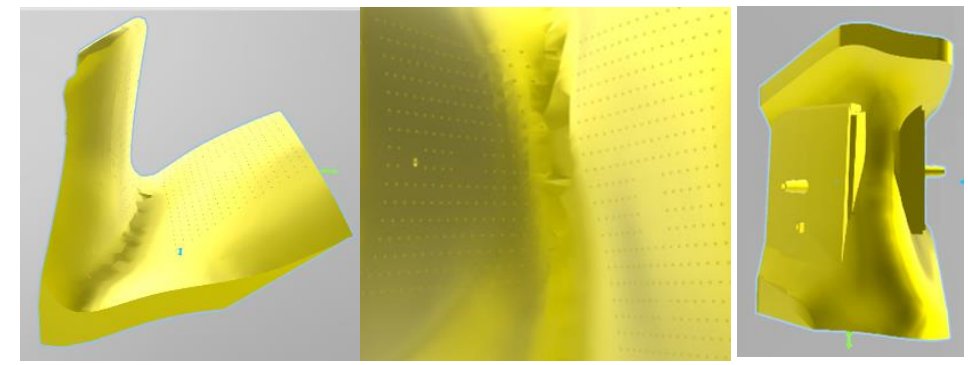

d)

Fig. 4. a) The anatomic model after it was subtracted the fully solid sweat glands module; b) The module after union operations between sweat glands module parts and anatomical surfaces; c) Thickness analysis; d) The final virtual model of armpit with sweat glands modules

The final virtual model of the armpit with integrated sweat glands module is presented in Fig. 4d. Starting from information about human body sweat glands, a suitable armpit with sweat glands was designed and SLA-processed (Fig. 5a). The developed device contains more than 600 outlet glands and its solid outer-boundary layer mimics the anatomical shape of an armpit area at real scale. Moreover, this part was equipped with two sensors to measure the humidity and the temperature, an electronically controlled pump and other accessories, which are required for future sweating tests (Fig. 5b).

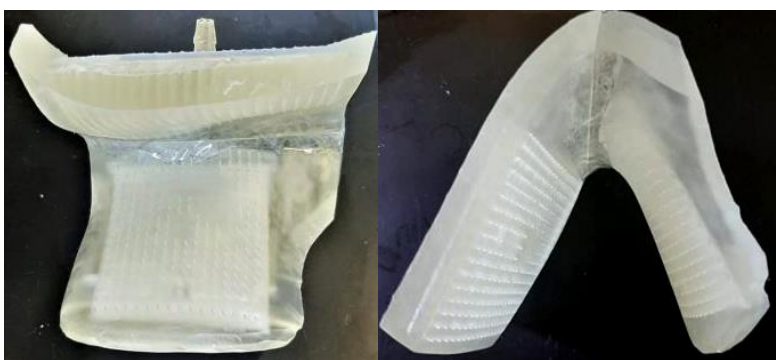

a)

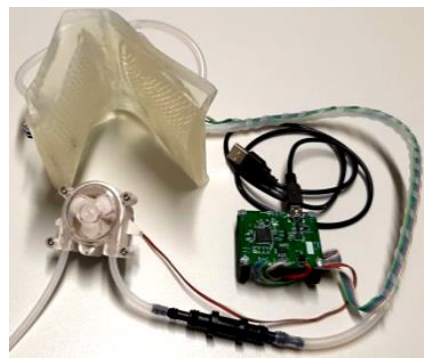

b)

Fig. 5. a) Armpit with SLA-manufactured sweat glands modules; b) Final sweat glands module

Furthermore, this sweating glands module prototype, manufactured with SLA, will be integrated into a mechatronic system, which contains additional hardware and software that needs to be developed. 


\section{Conclusion}

The study provides an in-depth overview of the design and SLA manufacturing of sweat glands modules which can have a high impact on the future practice in this field. It also explores the Additive Manufacturing benefits of fabricating an anatomic sweat glands system, which contains more than 600 outlets glands.

With the design freedom afforded by the SLA-process, the flow distribution is difficult to achieve on the atypically channels network developed. Because we designed a complex network of flow channels, just a theoretical estimation of the fluid flow distribution could be concluded and practical tests are required to evaluate the real fluid distribution of the present sweat glands module. The knowledge gained serves as the technical basis for the expansion of the overall sweating system. This is intended to lay the foundation for the process automation and optimization, which is an important element in the further development of the planned prototype.

Acknowledgement: This paper was supported the Human Capital Operational Programme agreement POCU/380/6/13/123927 financed from the European Social Fund.

\section{References}

1. D. Zavec, J. Balic, M. Ficko, B. Katalinić, (Ed.). Functional products development: advanced tools and concepts, DAAAM International, 2014. ISBN 978-3-901509-96-4.

2. Ke, Ying \& Raj, Uday \& Li, Ziqi \& Wang, Faming. (2018). Hotplate and thermal manikins for evaluating clothing thermal comfort.

3. N.A.S. Taylor, C.A Machado-Moreira, Extreme Physiology \& Medicine, 2, (2013).

4. I. Turcin, C. Cosma, A. Abdallah, N. Balc, 7th International Conference on Additive Technologies, Maribor, Slovenia, (2018).

5. A. Ispas, C. Cosma, A. Craciun, M. Constantiniuc, L. Lascu, D. Leordean, Journal of optoelectronics and advanced materials, 18, 904-912, (2016).

6. G. Armencea, C. Cosma, C. Dinu, F. Onisor, M. Lazar, P. Berce, N. Balc, M. Baciut, S. Bran, Particulate Science and Technology, DOI: 10.1080/02726351.2019.1578846, (2019).

7. Design Specs, Form 2 equipment, FormLabs USA, https://formlabs.com/3dprinters/form-2/design-specs/, (2019).

8. A. Popescu, L. Hancu, E. Sabau, Acta Technica Napocensis Series: Applied Mathematics, Mechanics, and Engineering, 61, 213-218, (2018).

9. C. Morar, A. Popescu, Acta Technica Napocensis Series: Applied Mathematics, Mechanics, and Engineering, 60, 319-324, (2017).

10. R.B.S Gowda, C.S. Udayagiri, D.N. Drakshayani, International Journal of Manufacturing Engineering, (2014).

11. C.K. Chua, K.F. Leong, C.S. Lim, Rapid Prototyping: Principles and Applications, Singapore, (2003).

12. M. Harničárová, J. Valíček, R. Čep, H. Tozan, J. Müllerová, R. Grznárik, International Journal Advanced Manufacturing Technology, 69, 81-91 (2013).

13. L. Sobotova, R. Kralikova, M. Badida, Key Engineering Materials, 635, 35-40, (2015).

14. C.S.M. Borzan, M.C. Dudescu, V. Ceclan, A. Trif, M. Ridzon, P. Berce, Materiale Plastice, 53, 1-5, (2016).

15. Retrieved from: https://support.formlabs.com/s/article/Choosing-the-Right-Mat (2019).

16. Retrieved from: https://simple.wikipedia.org/wiki/Axilla (19.09.2019).

17. K.B. Guo, L.C. Zhang, C. J. Wang, S.H. Huang, Int J Adv Manuf Technol, 33, (2007). 